\title{
Tubular duplication of the oesophagus presenting with dysphagia
}

Ashis Kumar Saha ${ }^{1}$ MD, DTM \& H, Arup Kumar $\underline{\text { Kundu }}^{1}$, MD

ABSTRACT Duplications of the alimentary tract are rare congenital malformations, with the ileum being the most commonly affected site, followed by the oesophagus. Among oesophageal duplications, cystic duplication is the most common and the tubular variety, the rarest. Herein, we report a rare case of tubular oesophageal duplication, complicated by adenosquamous carcinoma at the lower end of the oesophagus, in a 32-year-old man who presented with progressive dysphagia. Although proton pump inhibitors may relieve dysphagia, oesophagectomy and gastric interpositioning should be the first-line treatment for patients with tubular oesophageal duplication, in order to reduce the risk of malignant transformation at the lower end of the oesophagus.

Keywords: dysphagia, oesophagus, tubular duplication

\section{INTRODUCTION}

Duplication of the oesophagus, accounting for $15 \%$ of all digestive tract duplications, is a rare congenital malformation that occurs due to errors in embryogenesis. Oesophageal duplication occurs in three forms: (a) cystic, which may or may not communicate with the oesophageal lumen; ${ }^{(1)}(\mathrm{b})$ tubular; $^{(2)}$ and (c) diverticular, which is the rarest of the three. ${ }^{(3)}$

Tubular duplication usually consists of mucosal lining derived from the primitive foregut diverticulum, with or without the presence of muscular lining from the splanchnic mesoderm, and has an incidence of approximately 1 in 8,200 patients. ${ }^{(4)}$ Among oesophageal duplications, tubular duplication is rare compared to the cystic variety. Tubular duplication occurs due to the failure of vacuolisation of the primitive septum, which usually develops in the sixth gestational week. The most commonly affected sites of tubular duplication are the mid- and lower third of the oesophagus, ${ }^{(5)}$ whereas cystic oesophageal duplication is usually found in the lower third of the oesophagus. ${ }^{(6)}$ Patients with oesophageal duplications often present with dysphagia, respiratory distress and recurrent pneumonia, and occasionally, with gastrointestinal bleeding. ${ }^{(7)}$ Usually $70 \%-90 \%$ of these patients become symptomatic in childhood and are diagnosed before two years of age. ${ }^{(8)}$ However, few studies have reported the incidental discovery of oesophageal duplication in adult patients. ${ }^{(1,5)}$

In this study, we report a rare case of tubular duplication of the oesophagus, complicated by adenosquamous carcinoma at its lower end, in a 32-year-old man presenting with progressive dysphagia.

\section{CASE REPORT}

A 32-year-old man presented to our tertiary care hospital with a two-month history of progressive dysphagia to both solid and liquid intake. He had no relevant past history other than occasional

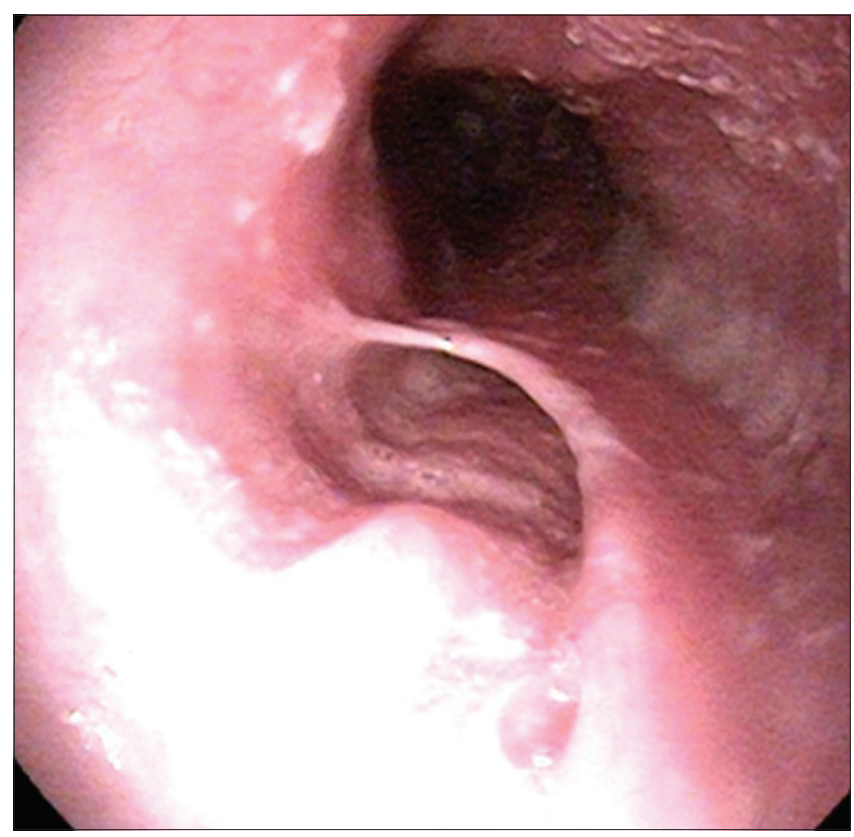

Fig. 1 Endoscopic image of the oesophageal duplication shows two lumina.

nocturnal retrosternal discomfort. There was no history of addiction. Physical examination was normal except for a few palpable leftsided supraclavicular lymph nodes. The patient was referred for barium swallow and fibreoptic oesophagoscopy (Fig. 1).

Barium oesophagography confirmed two oesophageal lumina in the mid- and lower oesophagus (Fig. 2). Upper gastrointestinal endoscopy revealed a thick septum arising on the left side of the mid-oesophagus (24 cm from the incisor teeth), which descended spirally downwards to merge with a polypoidal lesion (Fig. 3) a little above the lower end of oesophagus $(38 \mathrm{~cm}$ from the incisor teeth). The endoscope was negotiated through both sides of the septum toward the lower end of the oesophagus, but it could not be negotiated into the stomach cavity because of narrowing of the lumen due to the polypoidal lesion. Multiple biopsies were taken 


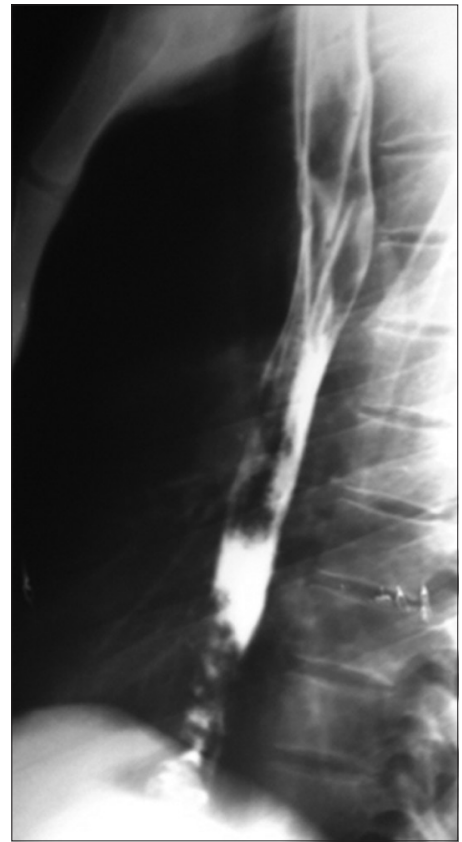

Fig. 2 Barium oesophagogram shows oesophageal duplication.

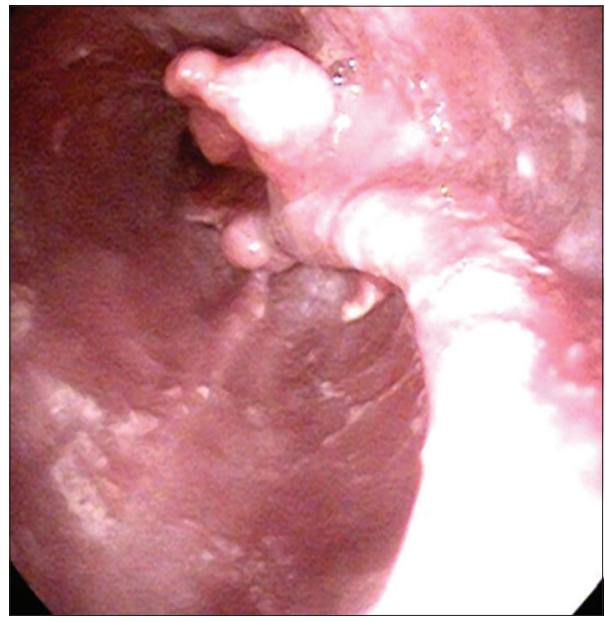

Fig. 3 Endoscopic image shows a polypoidal growth at the lower end of the oesophagus.

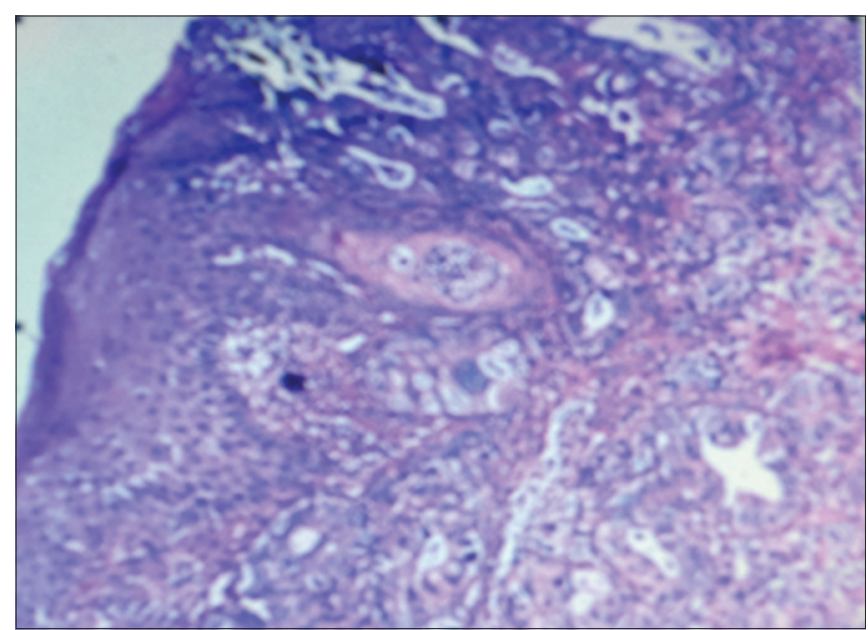

Fig. 4 Photomicrograph of the polypoidal growth shows adenosquamous oesophageal carcinoma with intestinal metaplasia (Haematoxylin \& eosin, $\times 100$ ). from the lesion for histopathological examination, which showed adenosquamous carcinoma of the oesophagus with evidence of scattered intestinal metaplasia (Fig. 4).

In view of the finding of adenosquamous carcinoma with intestinal metaplasia at the lower end of the oesophagus, radiotherapy was opted as the preferred treatment, and the patient was advised accordingly. However, in spite of repeated advice, he chose not to continue treatment and was lost to follow-up.

\section{DISCUSSION}

Oesophageal duplications are estimated to account for $10 \%-20 \%$ of foregut duplications in the posterior mediastinum. ${ }^{(9)}$ Unlike cystic duplications, tubular duplications usually communicate with the normal oesophagus. The earliest known description of tubular duplication was made by Kirwan et $\mathrm{al}^{(10)}$ and the second patient was reported by Kathe in 1907. ${ }^{(11)}$ Malignancies in patients with partial duplication have also been reported earlier. ${ }^{(12)}$ In this study, we report the case of a 32-year-old man who presented with progressive dysphagia and was diagnosed with tubular oesophageal duplication complicated by adenosquamous carcinoma at the lower end of the oesophagus.

In normal individuals, the lower oesophageal sphincter can unfold up to $2 \mathrm{~cm}$ as the stomach distends. ${ }^{(13)}$ As such, this portion of the lower oesophagus can be exposed to an unbuffered acid pocket that floats on the lipid layer after consumption of fatty meals, causing injury to its squamous epithelium. As a result, the epithelium becomes damaged, with evidence of basal cell hyperplasia followed by intestinal metaplasia. ${ }^{(8)}$ It is in such heterotopic mucosa that malignant change occurs. In our patient, the biopsy results revealed disarray of mucosal architecture with intestinal metaplasia. This metaplastic mucosa may have formed the basis for eventual malignant change.

Current literature suggests that oesophagectomy and gastric interpositioning should be considered as the first-line treatment for tubular duplication of the oesophagus in cases where there is no malignant transformation. ${ }^{(14)}$ Such an approach might even help to reduce the risk of malignant transformation at the lower end of the oesophagus. ${ }^{(15)}$ Proton pump inhibitor therapy is also thought to relieve the symptoms of dysphagia to a certain extent. ${ }^{(16)}$ However, as adenosquamous carcinoma with intestinal metaplasia was found at the lower end of oesophagus in our patient, radiotherapy became the treatment of choice. As our patient chose to discontinue treatment and was lost to follow-up despite our repeated advice, we were unable to provide him with appropriate treatment and ascertain outcome.

\section{REFERENCES}

1. Nakahara K, Fujii Y, Miyoshi S, et al. Acute symptoms due to huge duplication cyst ruptured into esophagus. Ann Thorac Surg 1990; 50:309-11. 
2. Dresler CM, Patterson GA, Taylor BR, Moote DJ. Complete foregut duplication. Ann Thorac Surg 1990; 50:306-8.

3. Ohbatake M, Muraji T, Yamazato M, et al. Congenital true diverticula of the esophagus: a case report. J Pediatr Surg 1997; 32:1592-4.

4. Arbona JL, Fazzi JG, M, Mayoral J. Congenital esophageal cyst: case report and review of literature. Am J Gastroenterol 1984; 79:177-82.

5. Kaneko E, Kohda A, Honda N, Kino I. Incomplete tubular duplication of esophagus with heterotopic gastric mucosa. Dig Dis Sci 1989; 34:948-51.

6. Snyder CL, Bickler SW, Gittes GK, Ramachandran V, Ashcraft KW Esophageal duplication cyst with esophageal web and tracheoesophageal fistula. J Pediatr Surg 1996; 31:968-9.

7. Haller JA, Shemeta DW, Donahoo JS, White JJ. Life threatening respiratory distress from mediastenal masses in infants. Am Thorax Surg 1975 19:364-70.

8. Phadke AY, Shah SK, Rajput SL, Bhandarkar PV, Abraham P. Incomplete tubular duplication of the esophagus lined by heterotopic gastric epithelium, presenting in adulthood. Endoscopy 2000; 32:S35-6.
9. Whitaker JA, Deffenbaugh LD, Cooke AR. Esophageal duplication cyst. Am J Gastroenterol 1980; 73:329-32

10. Kirwan WO, Walbaum PR, McCormack RJM. Cystic intrathoracic derivatives of the foregut and their complications. Thorax 1973; 28:424-8.

11. Kathe H. [Partielle verdoppelung der Speiseröhre]. Virchows Arch 1907; 190:78-92. German.

12. Boivin Y, Cholette JP, Lefebvre R. Accessory esophagus complicated by an adenocarcinoma. Can Med Assoc J 1964; 90:1414-7.

13. Flecher J, Wirz A, Henry E, et al. Studies of acid exposure immediately above the gastro-oesophageal squamocolumnar junction: Evidence of short segment reflux. Gut. 2004; 53:168-73.

14. Al-Majali RM, Al-Hiari AA, Alaween ZF, Ahmad KK. Mediastenal foregut duplication cyst. J Jordanian Roy Med Ser 2004; 11:48-50.

15. Mekki M, Belghith M, Krichene I, et al. [Esophageal duplication in children. Report of 7 cases]. Arch Pediatr 2001; 8:55-61. French.

16. Gopp AR. Anesthetic management of a patient with a mediastenal foregut duplication cyst: a case report. AANA journal. 2005; 73:55-61. 